\title{
Total flavonoids of Selaginella pulvinata alleviates cognitive impairment in mice
}

\author{
LIANZHU ZHANG ${ }^{1}$, YANG ZHANG ${ }^{2}$, YATING HOU ${ }^{3}$, HAIYAN LI $^{4}, \mathrm{CHIKUN} \mathrm{LI}^{4}$, JILE XIN $^{5}$, \\ NANA ZHOU ${ }^{1}$, QINGJIE $\mathrm{LI}^{4}$, YU SONG ${ }^{1}$ and ZHENGYAO ZHANG ${ }^{3}$ \\ ${ }^{1}$ College of Fisheries and Life Science, Hainan Tropical Ocean University, Sanya, Hainan 572022; \\ ${ }^{2}$ Department of Biopharmacy, School of Pharmaceutical Sciences, Jilin University, Changchun, Jilin 130022; \\ ${ }^{3}$ School of Life and Pharmaceutical Sciences, Dalian University of Technology, Dalian, Liaoning 116024; \\ ${ }^{4}$ The Hospital Affiliated to Changchun University of Chinese Medicine, Changchun, Jilin 130021; \\ ${ }^{5}$ Department of Biochemistry and Molecular Biology, College of Pharmacy, Henan University of Chinese Medicine, \\ Zhengzhou, Henan 450046, P.R. China
}

Received October 12, 2019; Accepted April 23, 2020

DOI: $10.3892 /$ br.2020.1315

\begin{abstract}
Cognitive impairment (CI) refers to dysfunctional cognition, which encompasses a spectrum of disorders, ranging from mild cognitive impairment to dementia. Any factor that results in cortical damage may cause CI. Total flavonoids of Selaginella pulvinata (TFSP), have shown promising antioxidant and protective effects in animal models. In the present study, mice were intraperitoneally treated with scopolamine, sodium nitrite or $45 \%$ ethanol to induce memory impairment, and the effects were assessed using a step-down test. After performing the behavioural test, hippocampal sections were collected for anatomical analysis, and the brain and serum levels of memory-related molecules were evaluated. The results showed that TFSP improved memory in a mouse model of CI significantly. Serum data were consistent with the behavioural results: TFSP increased blood acetylcholine levels through modulation of the acetylcholinesterase and choline acetyltransferase levels. It also ameliorated oxidative stress in neurons, increasing superoxide dismutase, glutathione peroxidase and inhibiting nitric oxide synthase levels in the brain. These results suggest that TFSP may exhibit potential as a clinical treatment for neurodegenerative diseases, including Parkinson's disease, Alzheimer's disease, and senile dementia.
\end{abstract}

\section{Introduction}

Both Selaginella tamariscina (Beauv.) and Selaginella pulvinata (Hook.et Grev.) are recorded in the Chinese

Correspondence to: Dr Zhengyao Zhang, School of Life and Pharmaceutical Sciences, Dalian University of Technology, 2 Linggong Road, Ganjingzi District, Dalian, Liaoning 116024, P.R. China

E-mail: zhengyaozhang@dlut.edu.cn

Key words: cognitive impairment, total flavonoids of Selaginella pulvinata, mouse model
Pharmacopoeia as Juanbai (1), a traditional Chinese herb. Selaginella, described as a 'whorlleaf stonecrop plant', has the ability to recuperate even after a long period of drought (2). According to traditional Chinese medicine, Selaginella is mild-natured, pungent, distributes to the liver and heart meridians, and improves blood circulation. Selaginella has been shown to exhibit antioxidant $(3,4)$, antidiabetic $(5,6)$, anti-tumor (7) and angiogenic properties (8). The primary active components in selaginella are flavonoids, which comprise $\sim 2.85 \%$ of the plant matter (9).

The physiological basis of cognitive impairment (CI), also referred to as cognitive deficit or cognitive disability, include aging, shrinkage or degeneration of brain tissue. These processes may result from abnormalities in the levels and actions of neurotransmitters and receptors, aggregation and modification of proteins in brain tissue, chronic cerebral ischemic injuries and diseases that result in insufficient blood supply to the brain (10). In addition, external factors such as infection, poisoning and metabolic dysfunction can lead to CI. $\mathrm{CI}$ is most common in individuals $>60$ years old. If not well controlled, CI will develop into senile dementia.

Models of memory impairment are useful for evaluating the effects of drugs on learning and memory processes. In the present study, memory impairment was induced using scopolamine, sodium nitrite or ethanol. Scopolamine is a competitive muscarinic cholinergic receptor antagonist that impairs memory acquisition (11). Sodium nitrite increases methemoglobin content in the blood, resulting in a lowered carrying capacity of oxygen, thus leading to brain tissue hypoxia, which impairs memory consolidation (12). Ethanol inhibits cortical activity, conditioned reflexes, RNA synthesis and protein synthesis, thereby impairing memory retrieval (13).

\section{Materials and methods}

Experimental animals. A total of 200 Kunming male and female mice, weighing 18-22 g, [animal 
certificate no. SCXK-(Ji) 2010-0005] were purchased from the Experimental Animal Center of Jilin University School of Basic Medicine. The present study was approved by the Animal Care and Welfare Committee of Changchun University of Chinese Medicine (Changchun, China) (approval no. 2012021). The mice were housed, 5 per cage, under standard laboratory conditions (temperature, $25 \pm 2^{\circ} \mathrm{C}$; humidity, $60 \pm 5 \%$; $12 \mathrm{~h}$ dark/light cycle), with free access to standard rodent chow and water.

Total flavonoids of Selaginella pulvinata (TFSP) acute toxicity test. Mice were observed for 3 days prior to testing, and those displaying abnormal appearance or abnormal behavior were excluded from further analysis. In a preliminary test, 6 mice were administered the maximum volume $(40 \mathrm{ml} / \mathrm{kg})$ of the maximum concentration $(10.5 \mathrm{~g} / 100 \mathrm{ml})$ of TFSP once, and observed for 14 days; and no deaths occurred. Therefore, this maximal dose was used in an acute toxicity test, in which TFSP was administered by gavage at day 0 , and observed for 14 days. Throughout the test, the hair, behavior, autonomic activity, respiration, oral and nasal secretions, diet, urine and time of death of each animal were observed. Animal weights were measured every other day. At the end of the experiment, mice were sacrificed by cervical dislocation, and the internal organs were harvested for examination.

Preparation of TFSP suspension. TFSP was prepared as described previously (14). Briefly, the high-dose suspension ( $40 \mathrm{mg} / \mathrm{ml}$ ) was prepared by mixing $2.8 \mathrm{~g}$ TFSP powder with $70 \mathrm{ml}$ distilled water. Medium $(20 \mathrm{mg} / \mathrm{ml})$ and low $(10 \mathrm{mg} / \mathrm{ml})$ doses were then diluted from the high dose suspension by adding distilled water accordingly. The prepared suspensions were stored at $4^{\circ} \mathrm{C}$.

Experimental model. Test animals were habituated to the test environment for 3 days before being randomly divided into groups. For each memory impairment model type, there were 5 groups ( $\mathrm{n}=10$ per group): control, CI, high-dose TFSP, medium-dose TFSP and low-dose TFSP. The control groups were administered distilled water by gavage and injected intraperitoneally with normal saline. The CI groups were administered distilled water by gavage and injected intraperitoneally with either scopolamine hydrobromide $(5 \mathrm{mg} / \mathrm{kg})$ or sodium nitrite $(90 \mathrm{mg} / \mathrm{kg})$ or $45 \%$ ethanol $(10 \mathrm{ml} / \mathrm{kg})$. The TFSP groups were administered with the indicated doses of TFSP suspension via gavage and injected intraperitoneally with either scopolamine hydrobromide $(5 \mathrm{mg} / \mathrm{kg})$ or sodium nitrite $(90 \mathrm{mg} / \mathrm{kg})$ or $45 \%$ ethanol $(10 \mathrm{ml} / \mathrm{kg})$. Drugs were administered once a day for 4 weeks.

Step-down test. Mice were placed in the control box of the step-down instrument for $1 \mathrm{~min}$. Then, at the onset of a 5-min training period, a $32 \mathrm{~V}$ electric current was applied to the floor. Mice respond by jumping onto the platform to escape the electric shock. Subsequently, when a mouse descended back down such that both of its feet touched the floor at the same time, it received a shock. Each time a mouse descended down to the electrified floor, it was considered an error. The following day, testing was conducted; each mouse was placed on the platform, and the latency of the first jump as well as number of jumps within a 5-min testing period were recorded.

Tissue collection and preparation of tissue sections. After the behavioral test on the last day, retroorbital blood was collected and then the mice were decapitated. Hippocampi were removed immediately and fixed in 10\% formaldehyde at room temperature for 1 week. The fixed tissues were rinsed repeatedly with water and stored in 10\% EDTA until decalcification was complete [the decalcifying solution was monitored and ammonium oxalate $(5 \% \mathrm{~g} / \mathrm{v})$ was added until it did not turn turbid]. Tissue blocks were dehydrated in an ascending series of ethanol (80, 90, 95 and 100\%) washed in xylene and embedded in paraffin before being sectioned transversely (4-5 $\mu \mathrm{m}$ thickness). The sections were then dewaxed in xylene, rehydrated in ethanol (100, 95, 90 and 80\%), stained with hematoxylin-eosin and toluidine blue at room temperature for $5 \mathrm{~min}$, and observed under a light microscope at a magnification of $\mathrm{x} 40$.

Measurement of biochemical indicators. The mice brains were separated and frozen at $-20^{\circ} \mathrm{C}$. Brains were unfrozen, $100 \mathrm{mg}$ of each brain was weighed and homogenized with pre-cooled normal saline, then centrifuged at $1,000 \mathrm{x} g$ for $5 \mathrm{~min}$ at $4^{\circ} \mathrm{C}$. The levels of memory-related molecules in the supernatant were assessed using specific kits according to the manufacturer's protocol [total superoxide dismutase assay kit, malondialdehyde (MDA) assay kit (cat. no. 20120916), nitric oxide (NO) assay kit (cat. no. 20120803), total nitric oxide synthase (NOS) assay kit (cat. no. 20121019), acetylcholine assay kit (cat. no. 20121029), acetylcholinesterase assay kit (cat. no. 20120822), choline acetyltransferase assay kit (cat. no. 20120902), reduced glutathione (GSH) assay kit (cat. no. 20120910) and glutathione peroxidase (GSHPx) assay kit (cat. no. 20121025)]. Kits were purchased from Nanjing Jiancheng Institute of Biology) (Nanjing, China).

Statistical analysis. All results are presented as mean \pm standard deviation. Data were compared across the three groups using a one-way ANOVA with a post-hoc Tukey-Kramer test. $\mathrm{P}<0.05$ was considered to indicate a statistically significant difference.

\section{Results}

TFSP acute toxicity test. Of the 20 test mice (10 each male and female) administered the maximum volume $(40 \mathrm{ml} / \mathrm{kg})$ of TFSP suspension $(10.5 \mathrm{~g} / 100 \mathrm{ml})$ by gavage daily for 14 days, none died or exhibited abnormal reactions, and no abnormalities were observed in their dissected organs (data not shown). The body weights of the mice increased gradually (Fig. 1). Thus, the experimental doses of TFSP used were $1 / 5(800 \mathrm{mg} / \mathrm{kg})$, $1 / 10(400 \mathrm{mg} / \mathrm{kg})$ and $1 / 20(200 \mathrm{mg} / \mathrm{kg})$ of the maximum dose, all of which were considered to be safe.

Behavioral effects of TFSP on scopolamine model mice. The scopolamine group displayed shorter mean latency to error and a greater mean number of errors compared with the control group (both $\mathrm{P}<0.001$ ). Mice treated with high and medium doses of TFSP had significantly longer error 


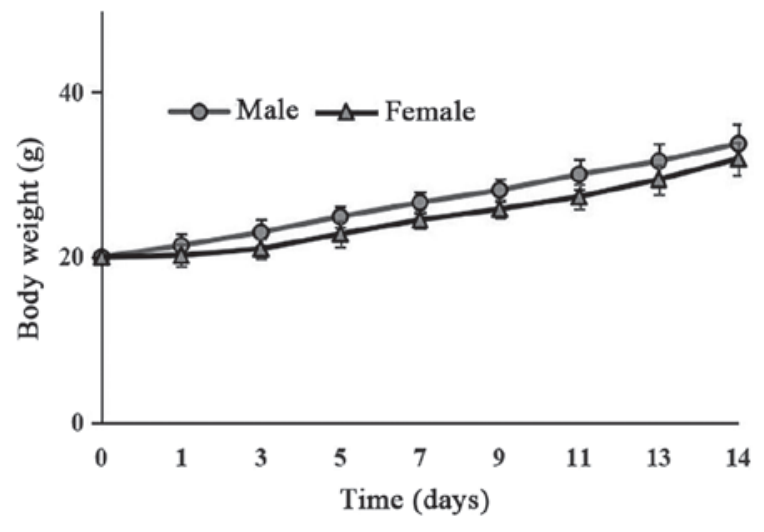

Figure 1. Effect of TFSP on body weight of mice. TFSP was administered on day $0 . n=10$ per group. TFSP, total flavonoids of Selaginella pulvinata.

latencies and fewer errors compared with those treated with scopolamine alone $(\mathrm{P}<0.05$; Fig. 2). Pathological analysis showed that scopolamine reduced hippocampal neuron counts significantly, and the cells observed were sparsely arranged and disordered (Fig. 3B). These effects were partially reversed in mice brains treated with TFSP (400 and 800 mg/kg; Fig. 3C-E).

Effects of TFSP on cholinergic molecules in brain tissue. Mice treated with scopolamine had lower levels of acetylcholine in the brain compared with the untreated controls. A high-dose of TFSP increased the levels of acetylcholine in the brain $(\mathrm{P}<0.05$; Fig. 4), reduced the activity of the acetylcholinesterase and increased the activity of the acetylcholine-biosynthesizing enzyme choline acetyltransferase (both $\mathrm{P}<0.05$, Fig. 5). Medium and low doses of TFSP did not exert any significant effects.

Behavioral effects of TFSP on mice treated with sodium nitrite. Mice treated with sodium nitrite displayed a significantly shorter mean error latency and a greater mean number of errors compared with the untreated controls $(\mathrm{P}<0.01$; Fig. 6). All TFSP doses prolonged error latency significantly, and the high and medium doses of TFSP reduced the number of errors significantly compared with the model group $(\mathrm{P}<0.05)$.

Pathological images of toluidine blue staining showed that mice injected with sodium nitrite had fewer hippocampal neurons, and the cells were sparsely arranged and disordered. Treatment with TFSP appeared to ameliorate these effects (Fig. 7).

Effects of TFSP on MDA content and SOD activity in brain tissue of mice treated with sodium nitrite. Compared with the control group, the MDA content in the brains of CI mice model was increased $(\mathrm{P}<0.05)$, and SOD activity was decreased $(\mathrm{P}<0.01)$, suggesting that sodium nitrite induced oxidative stress. TFSP significantly reduced MDA content $(\mathrm{P}<0.05$, Fig. 8) and increased SOD activity $(800 \mathrm{mg} / \mathrm{kg}, \mathrm{P}<0.01 ; 400$ and $200 \mathrm{mg} / \mathrm{kg}, \mathrm{P}<0.05$ Fig. 9).

Effects of TFSP on NO content and NOS activity in brain tissues of mice treated with sodium nitrite. Levels of NO and activity of NOS were higher in the brains of the model
A
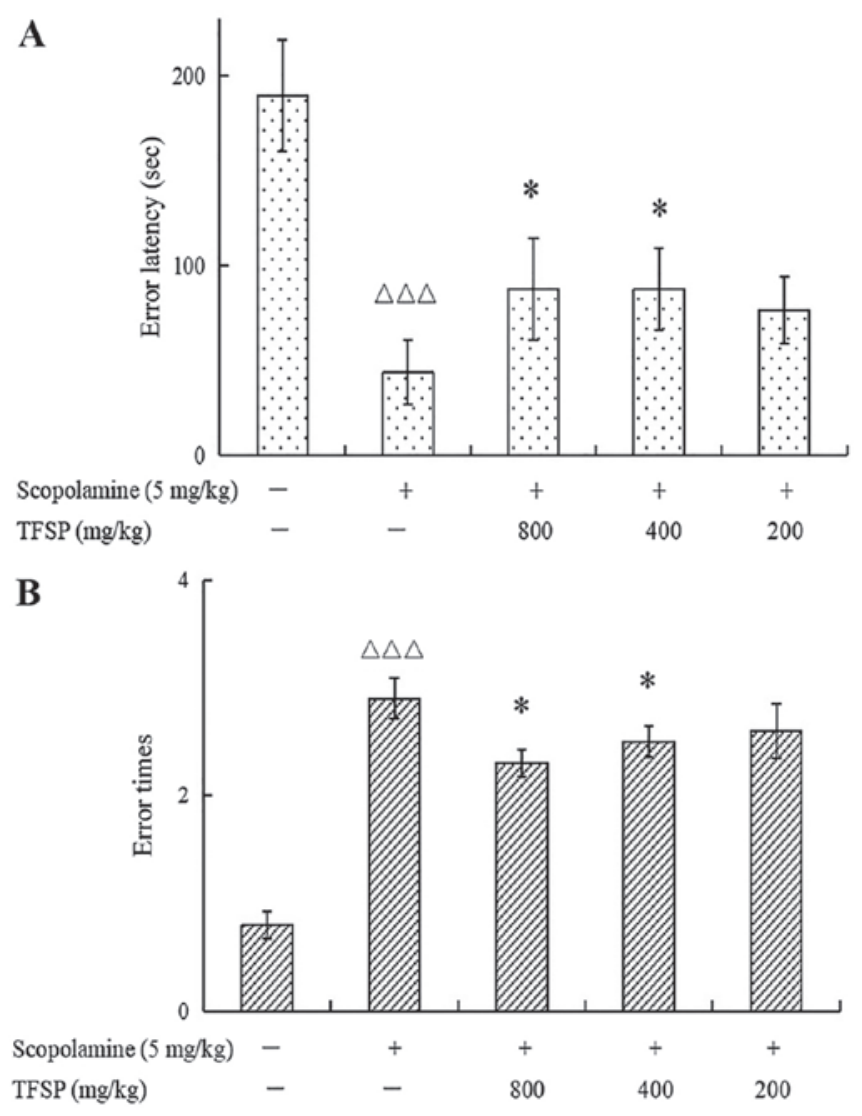

Figure 2. Effect of TFSP on the behavior of scopolamine-induced CI mice model in a step-down test. Compared with the mice administered scopolamine, but with no TFSP treatment, mice treated with high $(800 \mathrm{mg} / \mathrm{kg})$ and medium doses $(400 \mathrm{mg} / \mathrm{kg}$ ) TFSP exhibited (A) significantly longer error latency and (B) significantly fewer errors. $\mathrm{n}=10$ per group. ${ }^{\Delta \Delta \Delta} \mathrm{P}<0.001$ vs. untreated controls. ${ }^{*} \mathrm{P}<0.05$ vs. mice administered scopolamine, but with no TFSP treatment. TFSP, total flavonoids of Selaginella pulvinata; CI, cognitive impairment.

mice compared with the untreated controls $(\mathrm{P}<0.01)$. High and medium doses of TFSP significantly reduced NO content $(\mathrm{P}<0.05)$ and NOS activity $(\mathrm{P}<0.01$; Fig. 10$)$.

Effects of TFSP on GSH content and GSH-Px activity in brain tissues of mice treated with sodium nitrite. Levels of GSH and GSH-Px activity were significantly lower in the brains of the model mice compared with the untreated controls $(\mathrm{P}<0.01)$, suggesting that the brain tissues of the model group were in a state of oxidative damage. Treatment with medium and high doses of TFSP increased GSH content (Fig. 11) and GSH-Px activity significantly (Fig. 12).

TFSP improves impairments in memory retrieval induced by ethanol. Both the latency to error and the number of errors were significantly worse in ethanol-treated mice compared with the controls $(\mathrm{P}<0.001)$. Compared with the model group, all three TFSP doses significantly prolonged error latency $(\mathrm{P}<0.01)$ and reduced the number of errors $(\mathrm{P}<0.05$; Fig. 13).

\section{Discussion}

TFSP contributes to the improvement of behavior in mice with memory impairments induced by scopolamine, sodium nitrite 
$\mathbf{A}$

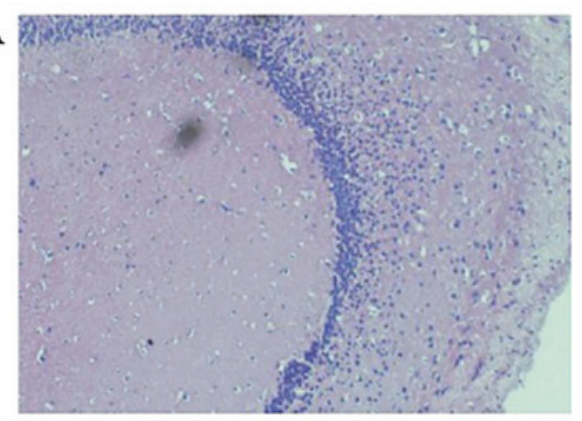

C

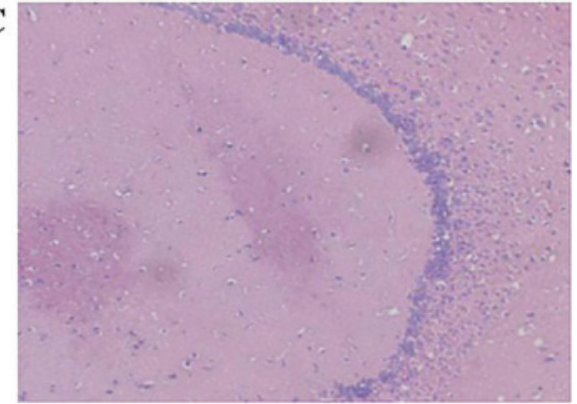

$\mathbf{E}$

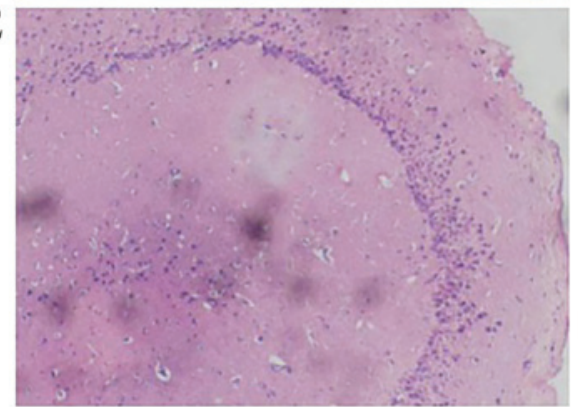

B

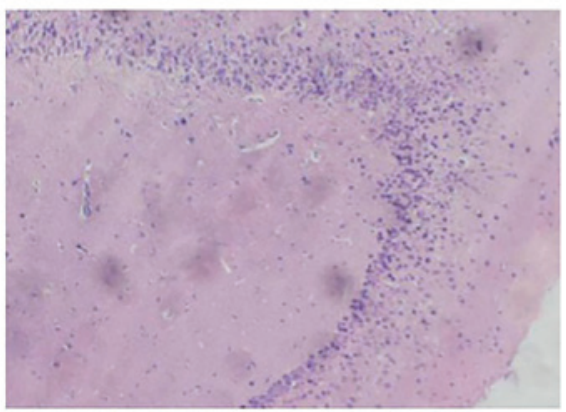

D

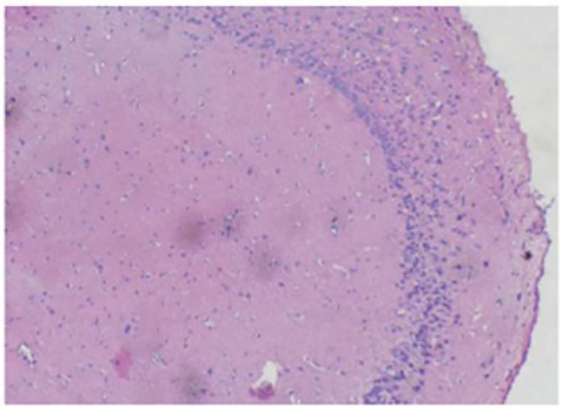

Figure 3. Effect of TFSP on the hippocampus of mice in scopolamine-induced CI mice model. (A) Control hippocampus, with densely packed and ordered cells. (B) Model hippocampus, with disorganized and scattered cells. Scopolamine-induced CI mice model treated with (C) $800 \mathrm{mg} / \mathrm{kg}$, (D) $400 \mathrm{mg} / \mathrm{kg}$ or (E) $200 \mathrm{mg} / \mathrm{kg}$ TFSP, showing the dose-dependent effects of TFSP. TFSP, total flavonoids of Selaginella pulvinata; CI, cognitive impairment. Magnification, x40. $\mathrm{n}=10$ per group.

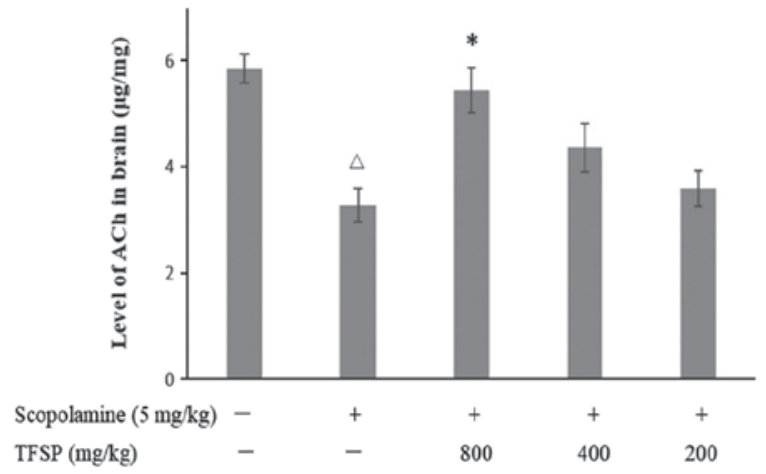

Figure 4. TFSP increases ACh content in the brains of scopolamine-induced CI model mice in a dose-dependent manner. $\mathrm{n}=10$ per group. ${ }^{\Delta} \mathrm{P}<0.05$ vs. untreated controls; " $\mathrm{P}<0.05$ vs. mice administered scopolamine, but with no TFSP treatment. ACh, acetylcholine; TFSP, total flavonoids of Selaginella pulvinata; $\mathrm{CI}$, cognitive impairment.

or $45 \%$ ethanol. TFSP treatment increased error latencies and reduced the number of errors in the step-down behavioral test. Furthermore, TFSP appeared to protect against hippocampal damage induced by these treatments as it associated with a reduced loss and disordering of hippocampal cells. These results suggest that TFSP may ameliorate CI at a cellular level.

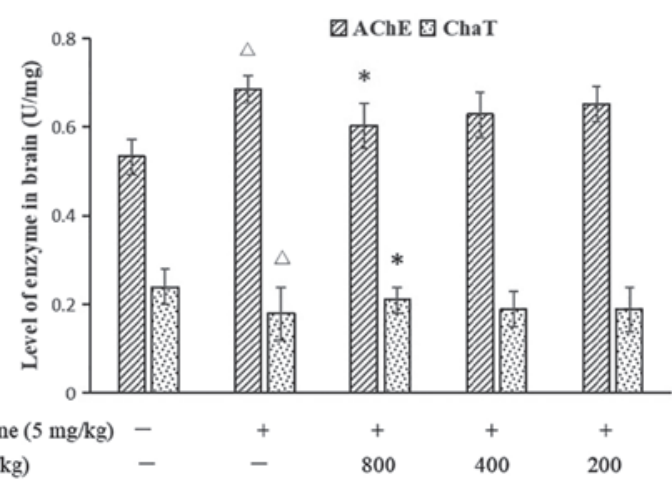

Figure 5. TFSP regulates AChE and ChaT activity in the brains of scopolamine-induced CI model mice. $\mathrm{n}=10$ per group. ${ }^{\Delta} \mathrm{P}<0.05$ vs. untreated controls; ${ }^{*} \mathrm{P}<0.05$ vs. mice administered scopolamine, but with no TFSP treatment. AChE, acetylcholinesterase; ChaT, choline acetyltransferase; TFSP, total flavonoids of Selaginella pulvinata; CI, cognitive impairment.

The content of acetylcholine in brain tissue is closely associated with cognitive function, and is dependent on the relative activities of acetylcholinesterase and choline acetyltransferase. Activated acetylcholinesterase breaks down acetylcholine, whereas activated choline acetyltransferase promotes synthesis of acetylcholine (15). Scopolamine mimics 
A

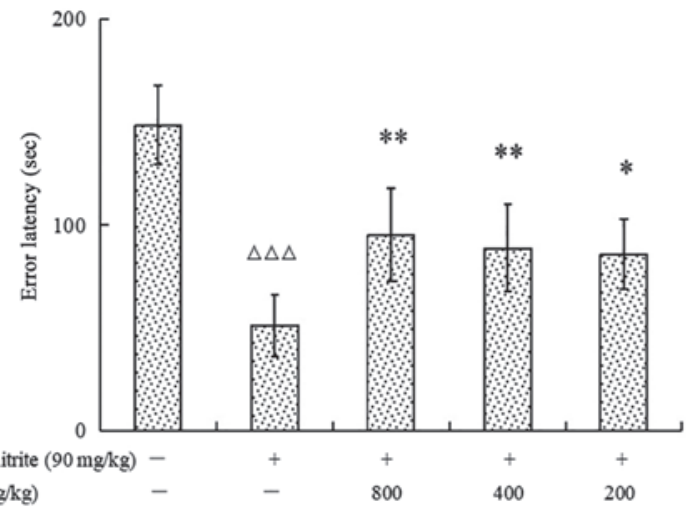

B

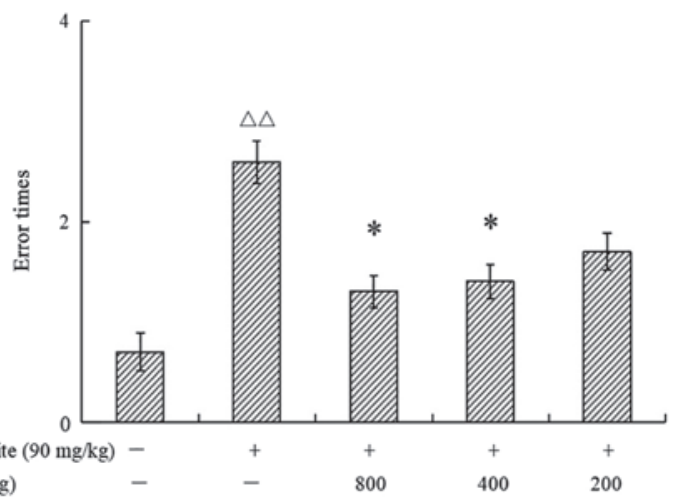

Figure 6. Effect of TFSP on the behavior of sodium nitrite-induced CI mice model in a step-down test. Compared with the mice administered sodium nitrite, but with no TFSP treatment, mice treated with high $(800 \mathrm{mg} / \mathrm{kg}$ ) and medium doses (400 mg/kg) TFSP had (A) a longer error latency and (B) fewer errors. $\mathrm{n}=10$ per group. ${ }^{\Delta \Delta} \mathrm{P}<0.01,{ }^{\Delta \Delta \Delta} \mathrm{P}<0.001$ vs. untreated controls; ${ }^{*} \mathrm{P}<0.05,{ }^{* *} \mathrm{P}<0.01$ vs. mice administered sodium nitrite, but with no TFSP treatment. TFSP, total flavonoids of Selaginella pulvinata; CI, cognitive impairment.
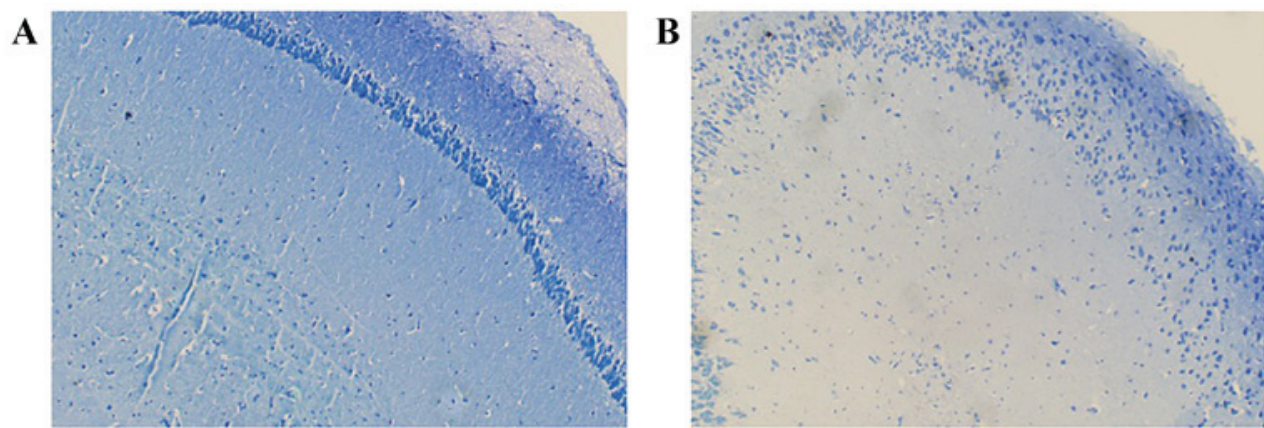

C

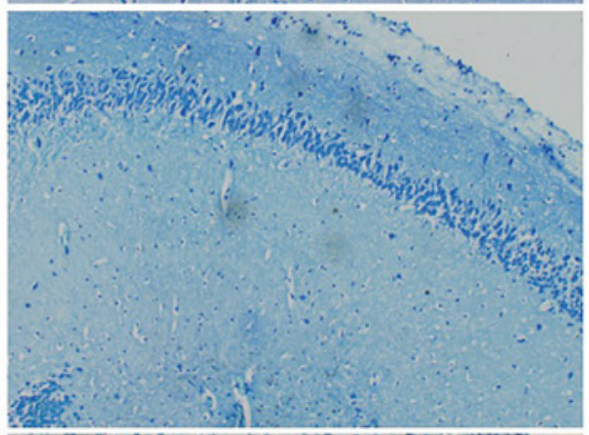

D

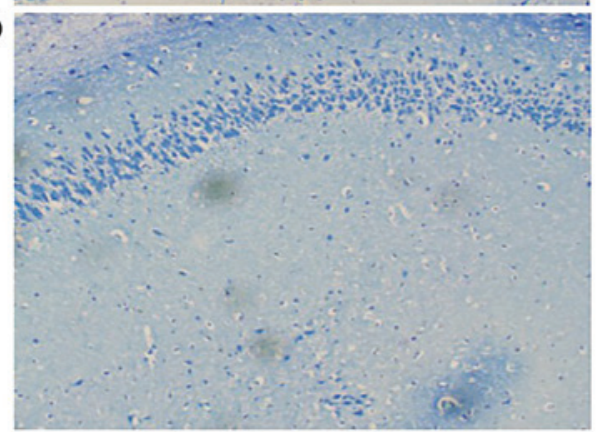

$\mathbf{E}$

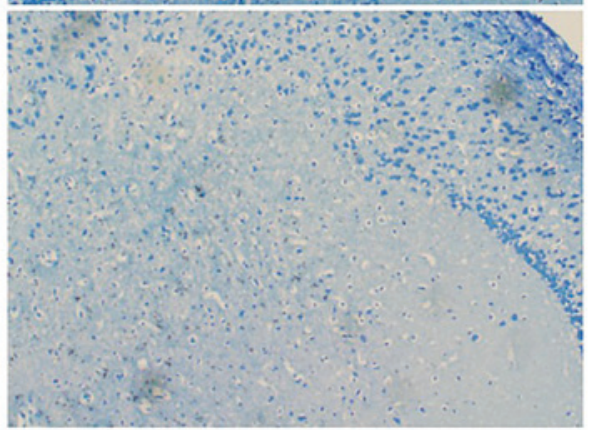

Figure 7. Effect of TFSP on the hippocampus in a sodium nitrite-induced CI mouse model. (A) Control hippocampus, with densely packed and ordered cells. (B) model hippocampus, with disorganized and scattered cells. Sodium nitrite-induced CI mice treated with (C) $800 \mathrm{mg} / \mathrm{kg}$, (D) $400 \mathrm{mg} / \mathrm{kg}$ or (E) $200 \mathrm{mg} / \mathrm{kg}$ TFSP, showing the dose-dependent effects of TFSP. Magnification, $\mathrm{x} 40 . \mathrm{n}=10$ per group. TFSP, total flavonoids of Selaginella pulvinata; CI, cognitive impairment.

the memory dysfunction caused by insufficient acetylcholine by blocking muscarinic receptors $(16,17)$. The results of the present study showed that TFSP may exhibit therapeutic effects on scopolamine-induced memory dysfunction via regulation of these key cholinergic enzymes.
Sodium nitrite leads to CI by inducing hypoxia (18), and also contributes to brain damage by disrupting redox reactions and producing large quantities of peroxides and free radicals (such as MDA and NO) (19). The resulting hypoxic environment decreases the activity of antioxidant enzymes, such as 


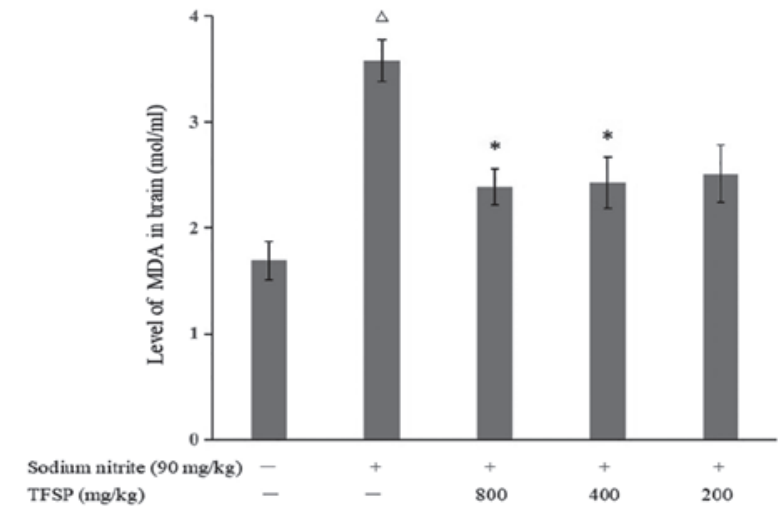

Figure 8. TFSP limits MDA accumulation in the brains of sodium nitrite-induced $\mathrm{CI}$ model mice. $\mathrm{n}=10$ per group. ${ }^{\Delta} \mathrm{P}<0.05$ vs. untreated controls; "P<0.05 vs. mice administered sodium nitrite, but with no TFSP treatment. TFSP, total flavonoids of Selaginella pulvinata; CI, cognitive impairment; MDA, malondialdehyde.

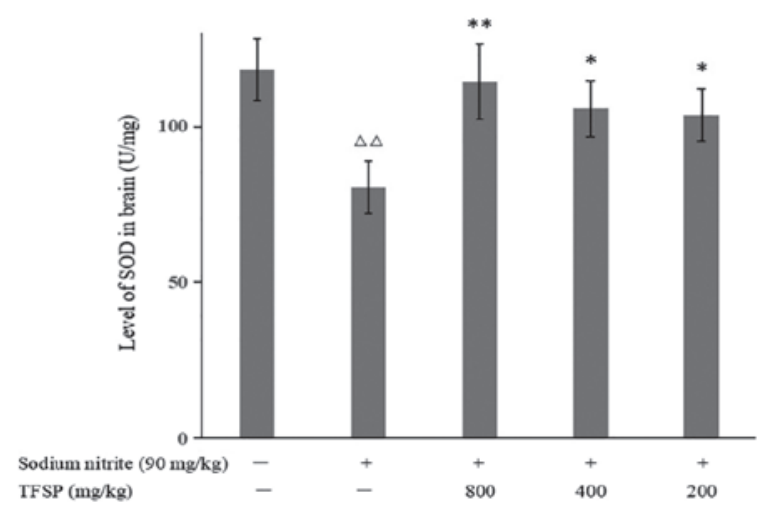

Figure 9. TFSP upregulates SOD activity in the brains of sodium nitrite-induced $\mathrm{CI}$ model mice. $\mathrm{n}=10$ per group. ${ }^{\Delta \Delta} \mathrm{P}<0.01$ vs. untreated controls; ${ }^{*} \mathrm{P}<0.05,{ }^{* *} \mathrm{P}<0.01$ vs. mice administered sodium nitrite, but with no TFSP treatment. TFSP, total flavonoids of Selaginella pulvinata; CI, cognitive impairment; SOD, superoxide dismutase.

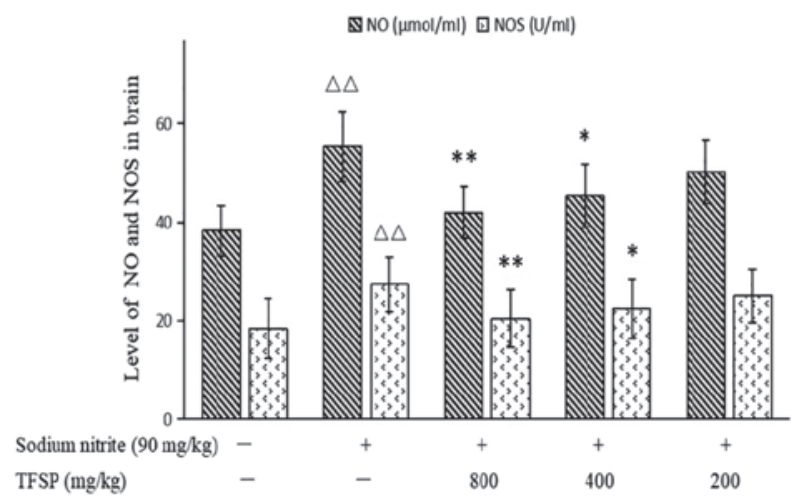

Figure 10. TFSP regulates NO content and NOS activity in the brains of sodium nitrite-induced CI model mice. $\mathrm{n}=10$ per group. ${ }^{\Delta \Delta} \mathrm{P}<0.01$ vs. untreated controls; ${ }^{*} \mathrm{P}<0.05,{ }^{* *} \mathrm{P}<0.01$ vs. mice administered sodium nitrite, but with no TFSP treatment. TFSP, total flavonoids of Selaginella pulvinata; CI, cognitive impairment; NO, nitric oxide; NOS, nitric oxide synthase.

SOD and GSH-Px, resulting in an accumulation of peroxidation products and free radicals, thereby further aggravating tissue damage. The results of the present study demonstrated

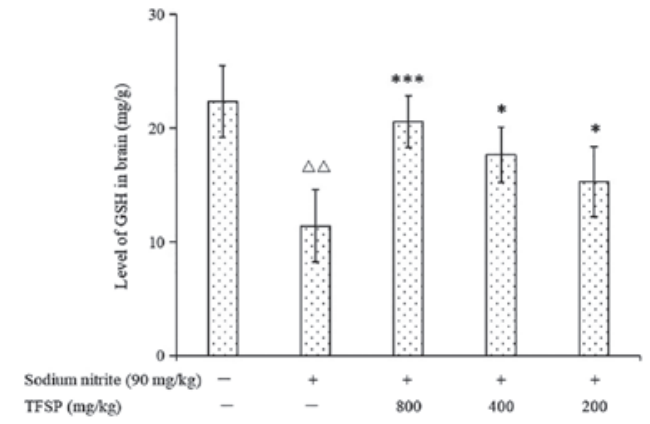

Figure 11. TFSP upregulates GSH content in the brains of sodium nitrite-induced CI model mice. $\mathrm{n}=10$ per group. ${ }^{\Delta \Delta} \mathrm{P}<0.01$ vs. untreated controls; ${ }^{*} \mathrm{P}<0.05,{ }^{* * *} \mathrm{P}<0.001$ vs. mice administered sodium nitrite, but with no TFSP treatment. TFSP, total flavonoids of Selaginella pulvinata; CI, cognitive impairment; GSH, glutathione.

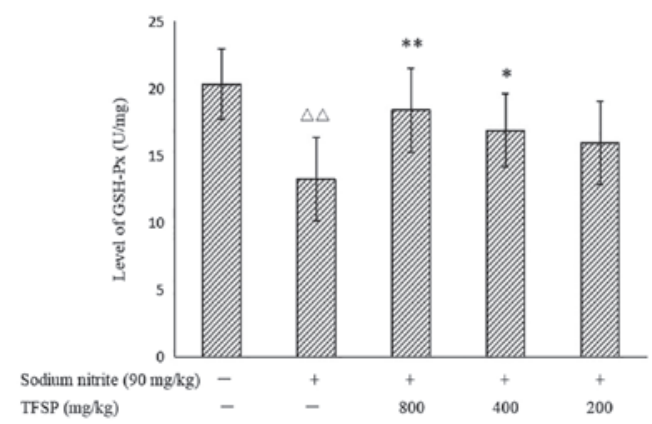

Figure 12. TFSP upregulates GSH-Px activity in the brains of sodium nitrite-induced CI model mice. $\mathrm{n}=10$ per group. ${ }^{\Delta \Delta} \mathrm{P}<0.01$ vs. untreated controls; ${ }^{*} \mathrm{P}<0.05,{ }^{* *} \mathrm{P}<0.01$ vs. mice administered sodium nitrite, but with no TFSP treatment. TFSP, total flavonoids of Selaginella pulvinata; CI, cognitive impairment; GSH-Px, glutathione peroxidase.

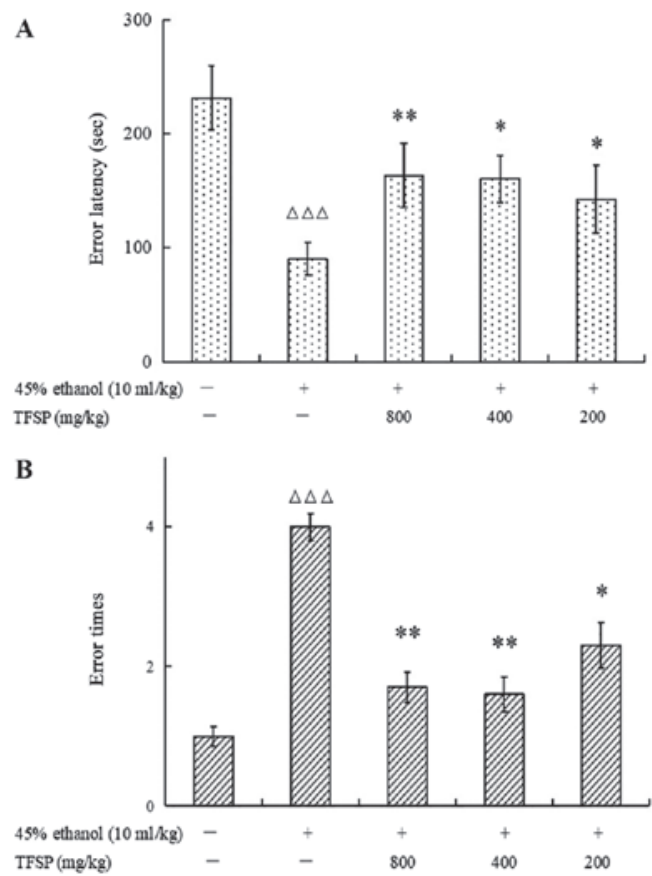

Figure 13. Effect of TFSP on the behavior of ethanol-induced CI mice model in a step-down test. Compared with the model mice, mice treated with TFSP exhibited (A) a longer error latency and (B) reduced error times. $\mathrm{n}=10$ per group. ${ }^{\Delta \Delta} \mathrm{P}<0.001$ vs. controls; ${ }^{*} \mathrm{P}<0.05,{ }^{* * *} \mathrm{P}<0.01$ vs. mice administered ethanol, but with no TFSP treatment. TFSP, total flavonoids of Selaginella pulvinata; $\mathrm{CI}$, cognitive impairment. 
that TFSP promotes favorable regulation of peroxides, free radicals and antioxidant enzymes, supporting the protection and repair of brain tissue, and thus cognition.

NO acts as reactive oxygen, and produces opposing effects on acetylcholine release in neuronal Aplysia synapses, dependent on the excitatory or the inhibitory nature of the synapse (20). In the present study, TFSP reduced NO and acetylcholinesterase levels in the serum and alleviated cognitive dysfunction in a similar manner to benazepril hydrochloride does (21).

Estrogen serves an important role in cognition (22). Flavonoids in Selaginella pulvinata have estrogenic $(23,24)$ and neuroprotective effects (25), that may have contributed to the relief of CI observed in the present study. It may also improve the cholinergic system through its estrogen-like effects, although this requires further study to confirm.

In conclusion, TFSP showed no significant acute toxicity in mice, and exerted a protective effect in several mouse models of CI. TFSP was associated with improvements in both cytological and behavioral measures. These results suggest that TFSP may be a promising treatment for CI. Further investigations on TFSP should focus on the active component(s), and additional mouse models of cognition, such as a maze test should be used to evaluate efficacy, before assessing its suitability in humans.

\section{Acknowledgements}

We would like to thank Mr Quancheng Zhao (Jilin Academy of traditional Chinese Medicine), Mrs Xiyan Ou, Mr Xiaobing Li and Mr Yunlu Ding (Chunchun University of Chinese Medicine), Mr Xuefeng Lv (Songyuan Food and Drug Administration) and Mrs Lianping Wang (Xiuzheng Pharmaceutical Group Co., Ltd.) for their experimental help.

\section{Funding}

This study was funded by Sanya Institute and Local Science and Technology Project (grant no. 2019YD11) and Hainan Tropical Ocean University Scientific Research Starting Foundation for PhD (grant no. RHDXB201708).

\section{Availability of data and materials}

The datasets used and/or analyzed during the present study are available from the corresponding author on reasonable request.

\section{Authors' contributions}

LZ conceived the experiments, analyzed the results, and wrote and edited the manuscript. YZ and YH wrote the manuscript, performed the experiments and analyzed the results. HL, CL, JX, NZ, and QL performed the experiments and analyzed the results. YS conceived the experiments and wrote the manuscript. ZZ designed the study, analyzed data and edited the manuscript. All authors read and approved the final manuscript.

\section{Ethics approval and consent to participate}

The present study was approved by the Animal Care and Welfare Committee of Changchun University of Chinese Medicine (Changchun, China) (approval no. 2012021).

\section{Patient consent for publication}

Not applicable.

\section{Competing interests}

The authors declare that they have no competing interests.

\section{References}

1. Chinese Pharmacopoeia Commission. Chinese Pharmacopoeia, 2015. http://db.ouryao.com/yd2015/view.php?v=txt\&id=353

2. Nanjing University of Chinese Medicine. Great Dictionary of Chinese Medicine, 2006.

3. Zheng XK, Wang WW, Zhang L, Su CF, Wu YY, Ke YY, Hou QW, Liu ZY, Gao AS and Feng WS: Antihyperlipidaemic and antioxidant effect of the total flavonoids in Selaginella tamariscina (Beauv.) Spring in diabetic mice. J Pharm Pharmacol 65: 757-766, 2013.

4. Zhang Z, Sun T, Niu JG, HeZQ, Liu Y and Wang F: Amentoflavone protects hippocampal neurons: Anti-inflammatory, antioxidative, and antiapoptotic effects. Neural Regen Res 10: 1125-1133, 2015

5. Su C, Yang C, Gong M, Ke Y, Yuan P, Wang X, Li M, Zheng X and Feng W: Antidiabetic activity and potential mechanism of amentoflavone in diabetic Mice. Molecules 24: E2184, 2019.

6. Zheng X, Ke Y, Feng A, Yuan P, Zhou Y, Yu Y, Wang X and Feng W: The Mechanism by which amentoflavone improves insulin resistance in HepG2 cells. Molecules 21: pii: E624, 2016.

7. Yang JS, Lin CW, Hsieh YS, Cheng HL, Lue KH, Yang SF and Lu KH: Selaginella tamariscina (Beauv.) possesses antimetastatic effects on human osteosarcoma cells by decreasing MMP-2 and MMP-9 secretions via p38 and Akt signaling pathways. Food Chem Toxicol 59: 801-807,2013.

8. Zheng XK, Ning TL, Wang XL, Liu CX, Liu YY and Feng WS: Effects of total flavonoids and amntoflavone isolated from Selaginella tamariscina on human umbilical vein endothelial cells proliferation and VEGF expression. J Chin Pharm Sci 46: 998-1002, 2011.

9. Yan Y, Zhu HY, Ma L: Content determination of flavones in five genus of Selaginella from Guizhou province, China. J Yunnan Univ (Natural Science Edition) 32: 227-231, 2010.

10. Experts group of prophylaxis and treatment cognitive impairment in China. Expert consensus on prevention and treatment of cognitive impairment in China. Chinese Journal of Internal Medicine 45: 171-173, 2006.

11. Klinkenberg I and Blokland A: The validity of scopolamine as a pharmacological model for cognitive impairment: A review of animal behavioral studies. Neurosci Biobehav Rev 8: 1307-1350, 2010.

12. Vohra BP and Hui X: Improvement of impaired memory in mice by taurine. Neural Plast 4: 245-259, 2000.

13. Haab Lutte A, Huppes Majolo J, Reali Nazario L and Da Silva RS: Early exposure to ethanol is able to affect the memory of adult zebrafish: Possible role of adenosine. Neurotoxicology 69: 17-22, 2018.

14. Li QJ, Wang LS and Wang LP: Study on Extraction method of total flavonoids from Selaginella tamariscina (Beauv.) Spring. J Changchun Univ Trad Chin Med 28: 355-356, 2012.

15. Park D, Yang YH, Bae DK, Lee SH, Yang G, Kyung J, Kim D, Choi EK, Lee SW, Kim GH, et al: Improvement of cognitive function and physical activity of aging mice by human neural stem cells over-expressing choline acetyltransferase. Neurobiol Aging 34: 2639-2646, 2013.

16. Li B, Guo DY and Li L: Behavioral Comparison among three animal models mimicking Alzheimer's disease. Chi J Exp Anim 7: 40-45, 1999.

17. Xu JM and Yu HY: Impact of different dosage scopolamine on rat learning and mnemonic ability. J Suzhou Univ (Health Sciences) 26: 53-54, 2006.

18. Zhai ZL, Yan Y, Shang YZ: Improving effects of brevisvapine on chemicals-induced memory impairment in mice. Chin J Biochem Pharm 33: 61-63, 2012.

19. Liu XX, Zhao YY, Chen Chun S and Bai J. Effects of extract of Alpinia officinarum Hance on learning memory consolidation and free radical in mice. Chin Traditional Pat Med 32: 1105-1108, 2010. 
20. Mothet JP, Fossier P, Tauc L and Baux G: Opposite actions of nitric oxide on cholinergic synapses: Which pathways? Proc Natl Acad Sci USA 93: 8721-8726, 1996. https://pubmed.ncbi.nlm. nih.gov/?term=Opposite+actions+of+nitric+oxide+on+choliner gic+synapses\%3A+Which+pathways $\% 3 \mathrm{~F}$

21. Zhao Z, Zhao X and Xu J: The effects of benazepril hydrochloride on nitirc oxide, acetylcholine in serum and cerebrospinal fluid of vascular dementia. Shanxi Med J 4: 457-460, 2019. https://xueshu.baidu.com/usercenter/paper/show?paperid=1p6k 0jj0v46x0vx0ad6b06d06q344386\&site=xueshu_se or http://d. wanfangdata.com.cn/periodical/sxyyzz201904021

22. Krolick KN, Zhu Q and Shi H: Effects of estrogens on central nervous system neurotransmission: Implications for sex differences in mental disorders. Prog Mol Biol Transl Sci 160: 105-171, 2018.

23. Zheng XK, Zhang X, Wang XL, Zhang N, Yuan PP and Feng WS Effect of estrogen-like effective part of Selaginella tarmariscina on bone metabolism in ovariectomized rats. Zhong Yao Cai 10: 1826-1829, 2014 (In Chinese).
24. Zheng XK, Jiang Y, Pei SJ, Wang XL, Zhang N, Ke YY, Zhai YY and Feng WS: Experimental study on estrogenic activity of ten kinds of Selaginella tamariscina from ten different place of origin. Xian Dai Zhong Yi Yao 1: 238-242, 2015.

25. Choi RC, Zhu JT, Yung AW, Lee PS, Xu SL, Guo AJ, Zhu KY, Dong TT and Tsim KW: Synergistic action of flavonoids, baicalein, and daidzein in estrogenic and neuroprotective effects: A development of potential health products and therapeutic drugs against Alzheimer's disease. Evid Based Complement Alternat Med 2013: 635694, 2013.

This work is licensed under a Creative Commons Attribution-NonCommercial-NoDerivatives 4.0 International (CC BY-NC-ND 4.0) License. 